\title{
ANDREA DEL LUNGO, Come ridere sul serio. Forme dell' «esprit» in Balzac
}

\section{Marco Stupazzoni}

\section{OpenEdition}

\section{Journals}

\section{Edizione digitale}

URL: http://journals.openedition.org/studifrancesi/16506

DOI: 10.4000/studifrancesi. 16506

ISSN: 2427-5856

\section{Editore}

Rosenberg \& Sellier

\section{Edizione cartacea}

Data di pubblicazione: 1 juillet 2019

Paginazione: 173

ISSN: 0039-2944

\section{Notizia bibliografica digitale}

Marco Stupazzoni, «AndREA del Lungo, Come ridere sul serio. Forme dell'«esprit» in Balzac», Studi Francesi

[Online], 187 (LXIII | I) | 2019, online dal 01 juillet 2019, consultato il 25 janvier 2021. URL: http:// journals.openedition.org/studifrancesi/16506 ; DOI: https://doi.org/10.4000/studifrancesi.16506

Questo documento è stato generato automaticamente il 25 janvier 2021.

\section{(a) $\odot \Theta$}

Studi Francesi è distribuita con Licenza Creative Commons Attribuzione - Non commerciale - Non opere derivate 4.0 Internazionale. 


\title{
ANDREA DEL LUNGO, Come ridere sul serio. Forme dell'«esprit» in Balzac
}

\author{
Marco Stupazzoni
}

\section{NOTIZIA}

ANDREA DEL LUNGO, Come ridere sul serio. Forme dell'«esprit» in Balzac, in Modi di ridere. Forme spiritose e umoristiche della narrazione, a cura di Emanuele Zinato, Pisa, Pacini Editore, 2015, «I Libri dell'Associazione Sigismondo Malatesta. Studi di letterature comparate (seconda serie)» 18, pp. 113-133.

1 Si ride poco nei romanzi di Balzac: o per lo meno, non si ride abbastanza da poter legittimare la qualifica di «enfant et rieur» che lo scrittore si attribuiva in una lettera a Madame Hanska. In realtà, e questo importante contributo di Andrea Del Lungo ce lo dimostra, è possibile definire una tipologia del riso in Balzac che, nell'attualizzare la nozione di esprit, consente di relativizzare la serietà della narrazione «prendendo a oggetto i principi analitici e scientifici che la determinano, nell'ambito di una visione sociologica del reale, e di una relazione essenziale del romanzo balzacchiano con il sapere dell'epoca» (p.117). Assai differenti si rivelano, nei romanzi della Comédie humaine, le tipologie balzachiane del riso: esse sono riconducibili, da un lato, al modello teatrale della commedia; dall'altro, alle forme di narrazione umoristica ereditate dal romanzo settecentesco (Sterne). Nel rivalutare la nozione di esprit, Balzac offre un modello di riso particolarmente "aggressivo» che si esplicita a diversi livelli dal punto di vista del codice e del genere romanzesco: a livello linguistico, come parodia del reale e in riferimento ai principi analitici che fondano la creazione stessa. È proprio nell'ambito dei fondamenti della rappresentazione letteraria che Del Lungo individua i caratteri più originali e significativi dell'esprit balzachiano, la cui componente metaletteraria risulta strettamente funzionale a una nuova concezione sociologica del reale. Questa forma di comicità seria incarnata in alcuni personaggi della Comédie humaine (Grandet, Crevel, Grassou) - vittime del comico, ma protagonisti nella società si accompagna a una forma di umorismo intertestuale in cui l'esprit è funzionale a una 
rivisitazione parodica dei saperi dell'epoca. Il caso de La Physiologie du mariage è, in questo senso, esemplare: Balzac evoca i modelli di Rabelais e di Sterne per ridicolizzare i saperi libreschi ed enciclopedici contemporanei e rivalutare allo stesso tempo «la posizione di Balzac nel codice romanzesco del suo tempo» (p. 128). Assistiamo, in altri termini, a un rovesciamento e a una destabilizzazione, in quanto «fonte principale del riso» (p. 129) di quel metodo analitico e positivista i cui paradigmi costituiranno le fondamenta della sua immensa costruzione letteraria. 